\title{
A COMPETENCE EXECUTIVE COACHING MODEL
}

Authors:

Pieter Koortzen

Rudolf M. Oosthuizen²

\section{Affiliations:}

${ }^{1}$ Department of Industrial

Psychology and People

Management, University

of Johannesburg,

South Africa

${ }^{2}$ Department of Industrial and Organisational

Psychology, University of

South Africa, South Africa

Correspondence to:

Pieter Koortzen

email:

pieter_koortzen@yahoo.

com

\section{Postal address:}

Department of Industrial

Psychology and People

Management, University

of Johannesburg,

South Africa

\section{Keywords:}

training and

development needs; consulting; planning

implementation and evaluation; interventions; competencies; coaches

\section{Dates:}

Received: 08 June 2009

Accepted: 04 Mar. 2010

Published: 19 July 2010

How to cite this article: Koortzen, P., \&

Oosthuizen, R. (2010). A

competence executive

coaching model. SA

Journal of Industrial

Psychology/SA Tydskrif

vir Bedryfsielkunde, 36(1),

Art. \#837, 11 pages. DOI:

10.4102/sajip.v36i1.837

This article is available at:

http://www.sajip.co.za

(C) 2010. The Authors.

Licensee: OpenJournals

Publishing. This work

is licensed under the

Creative Commons

Attribution License.

\section{ABSTRACT}

Orientation: Psychologists in industry are increasingly required to provide executive coaching services in their organisations or as part of their consulting services. An evaluation of coaching models as well as the development needs of individuals being trained as coaches, both locally and internationally, has led the authors to believe that there is a need for a competence executive coaching model.

Research purpose: The purpose of this article is to address the training and development needs of these consulting psychologists by presenting a competence executive coaching model for the planning, implementation and evaluation of executive coaching interventions.

Research design, approach and method: The study was conducted while one of the authors was involved in teaching doctoral students in consulting psychology and executive coaching, specifically in the USA. The approach involved a literature review of executive coaching models and a qualitative study using focus groups to develop and evaluate the competence executive coaching model.

Main findings: The literature review provided scant evidence of competence executive coaching models and there seems to be a specific need for this in the training of coaches in South Africa. Hence the model that was developed is an attempt to provide trainers with a structured model for the training of coaches.

Contribution/value-add: The uniqueness of this competence model is not only described in terms of the six distinct coaching intervention phases, but also the competencies required in each.

\section{INTRODUCTION}

Numerous publications on the concepts of coaching and executive coaching have been published in the last ten years (Killburg \& Diedrich, 2007; Levinson, 2009; Palmer \& Whybrow, 2007). Although a great deal has been written on this topic, the body of knowledge still seems to be unintegrated and leaves some psychologists entering the field somewhat unsure and confused about the unique nature of executive coaching. Similarly, many different coaching models are presented in the literature, which may exacerbate the confusion. An evaluation of coaching models as well as the development needs of individuals being trained as coaches, locally and internationally, has led the authors to believe that there is a need for a competence executive coaching model. A review of current models, which is presented later in the article, focuses mostly on the tasks involved in a coaching process without describing the competences (outcomes) and the assessment criteria (criteria of success) in each phase. A competence model, however, can be used to describe the coaching process, the various competences and the assessment criteria with which trainers can determine the effectiveness of an executive coaching training programme and coaches can also evaluate their own performance. The goal of this article is therefore to describe the development and evaluation of a competence executive coaching model. As a point of departure it may be valuable to distinguish this concept from other related concepts, which may be more familiar to practising psychologists. Consulting psychologists, in particular, may already provide services that include mentoring, facilitation, consultation and counselling and may consider adding executive coaching to the list (Killburg \& Diedrich, 2007; Levinson, 2009). In order to develop and describe such a competence model, executive coaching should first be distinguished from other interventions such as facilitation and counselling. Executive coaching should also be defined, the roles and services of executive coaches clarified and the profile, competencies and qualities (characteristics) analysed. This article also describes and evaluates existing models.

The question can therefore be asked how executive coaching is different from the above-mentioned concepts. Mentor relationships are usually informal relationships that are based on proximity, common experience and the chemistry between the mentor and protégé (Torrance, 1984; Underhill, 2007). Mentors are usually older, seasoned professionals who take newer professionals under their wings. These mentors often worked in positions similar to those of the new leaders and are therefore able to provide information, guidance and encouragement relating specifically to the job. Douglas and McCauley (1999) argue that although one-on-one mentoring programmes may have advantages, they are frequently in conflict with the organisational culture. They also believe that mentoring programmes are not adequately supported by organisations when they are not part of a larger management development strategy. In response to these criticisms, the literature suggests that organisations have begun to implement alternative developmental programmes, which include executive coaching (Torrance, 1984; Underhill, 2007). It is believed that executive coaches may be able to provide a wider range of services to the coachee, which are not limited to specialist functional knowledge and which are aligned with the organisation's broader developmental strategy and culture.

Increasing dialogue between organisations representing coaching and mentoring, which has been stimulated in Europe by the European Mentoring and Coaching Council, is starting to break down some of these artificial barriers. It is becoming clearer that coaching and mentoring need to be defined 
differently in different contexts and that this is a potential strength as much as a current weakness. Obviously there are still many dogmatic statements about the distinctions between coaching and mentoring, but it is increasingly accepted that both coaching and mentoring may, in specific contexts:

- be relatively directive or non-directive

- require and draw upon the helper's experience

- be of long or short duration

- involve giving advice

- work with goals set by the learner or for the learner

- deal with significant transitions the learner wishes to make

- address broad personal growth ambitions (Clutterbuck, 2008).

Koortzen and Cilliers (2002) conceptualise facilitation from a person-centred approach as a process of providing an open and trusting climate where opportunities for learning can take place. In using the core conditions of respect, realness and empathy, the exploration of thoughts, feelings and behaviours are able to be facilitated, which leads to personal growth and ways to change behaviour in order to become a more fully functioning or self-actualised person. From this description it is clear that from time to time, executive coaches may assume the role as facilitator, but the role of executive coach is far broader While the facilitator role may be appropriate in addressing personal development needs, other roles include educator/ trainer, advisor and mentor.

Consultants often find themselves in situations that could best be described as 'coaching' (Killburg \& Diedrich, 2007). A client defines the situation as one in which he or she wants individual help to work on a personal issue, or a manager asks the consultant to work with an individual to improve job performance or overcome some developmental deficiencies. From this point of view, the consultant's job may be much broader than that of the coach in the sense that the client system is defined as more than the sum of the individual coaching projects in which members may be engaged. The degree of overlapping between coaching and consulting depends on who initiated the request for coaching, who is being coached, the role for which they are being coached and the issues for which they are being coached (Schein, 2005, 2006).

Three fundamentally different roles that the consultant can play in any client relationship need to be distinguished: the provider of expert information, the diagnostician and prescriber of remedies and the process consultant whose focus is on helping the client to help himself or herself (Schein, 1969, 1987, 1988, 1999). In all of these roles, which would include coaching, the overarching goal is to be helpful to the immediate client and mindful of the impact of interventions on the larger client system and community. The consultant must have the ability to move among these roles freely, but he or she must begin in the process mode. In order to ascertain in what way expertise or diagnosis and prescription are relevant to the client's needs, the consultant must establish a 'helping relationship' with the client, in which the latter can safely reveal the real problem. It is only by establishing such a relationship that the consultant can determine what kind of help the client really needs (Schein, 2006).

In the case of organisational consulting, a further complication is that the consultant will never understand the culture of the client system well enough to make accurate diagnoses or provide workable prescriptions. Therefore, in organisational consulting, the consultant and the client must become a team that jointly 'owns' the consequences of all diagnostic and remedial interventions. However, it must be made clear that it is the client who owns the problem and is ultimately responsible for the solution. The consultant thereby enters into a therapeutic relationship with the client system and can facilitate the improvement of the situation as the client defines it. Clearly then, coaching can be regarded as one kind of intervention that may be helpful to clients in certain circumstances. In this context, coaching establishes a set of behaviours that helps the client to develop a new way of seeing, feeling about and behaving in problematic situations (Schein, 2006).

Counselling is defined as listening, advising and referring when there is a poor attitude, personal problems or some outside influence causing performance problems. An effective counsellor listens, facilitates, refers, questions, explores options and acts as a confidant(e). A step-by-step model of an effective counselling session would include the following:

- Step 1: Prepare the employee, put him or her at ease, and ensure privacy.

- Step 2: Explore the problem using active listening techniques.

- Step 3: Encourage the employee to generate his or her own solutions and then show support.

- Step 4: Refer him or her, if necessary.

- Step 5: Follow up (Hart, Blattner \& Leipsic, 2007; Salters, 1997).

Coaching occurs in the workplace with the intention of improving a manager's interpersonal skills and ultimately his or her workplace performance. It is more issue-focused than counselling and occurs in a broader array of contexts including face-to-face sessions, meetings over the telephone and by email - and in a variety of locations away from work (Richard, 1999; Sperry, 1993, 1996). Coaching sessions can last from a few minutes to a few hours (Sperry, 1996; Bachkirova 2007), whereas counselling typically occurs in a 45 - to 50 -minute interval. Also, in coaching, as opposed to counselling, data are collected from many sources, including the individual manager, his or her superiors, peers, subordinates and family members (Brotman, Liberi \& Wasylyshyn, 1998; Diedrich, 1996; Harris, 1999; Kiel, Rimmer, Williams \& Doyle, 1996; Killburg, 1996; Peterson, 1996; Richard, 1999; Witherspoon \& White, 1996). Other differences include being able to be more directive in coaching (Levinson, 1996, 2002; Richard, 1999) and viewing the relationship between the manager and the coach as more collegial (Levinson, 1996, 2002; Tobias, 1996), because the need for manager self-disclosure may not be as great as it is for counselling clients (Saporito, 1996). According to Killburg (2000), although the principles of counselling can enhance coaching, the main difference is the depth to which issues are pursued and processed (Kampa-Kokesch \& Anderson, 2001).

In coaching, the coach may be the expert who teaches the employee how to improve work or job performance. In counselling, however, this approach will not work. The employee has to fix it and the manager's role is to facilitate the process by means of internal and external resources. According to Salters (1997), listen, confront appropriately, refer, support, and, as in coaching, keep the expectations of improvement front and centre. Coaching and counselling both require active listening techniques and hold out the expectation of improvement. Coaching requires a different approach to counselling. Counselling requires confidentiality and potentially has a greater risk of liability. In both techniques, the way in which feedback is given is crucial. It should be given in a positive not negative way. In counselling, progress is measured mainly by patient self-reports, while in coaching, performance is measured in more concrete numerical terms (Richard, 1999). Although the above discussion distinguishes coaching from the other interventions - namely, mentoring, facilitation, consulting and counselling, executive coaching has a specific context and particular goals.

\section{EXECUTIVE COACHING}

The coaching partnership often begins when the leader is engaged in a dilemma and feels trapped. The essence of executive coaching is to help leaders become 'unstuck' from their dilemmas and assist them to transfer their learning into results for the organisation. Coaches bring the kind of trained (yet natural) curiosity of a journalist or an anthropologist to the leader's work situation. In addition, coaches typically share 
conceptual frameworks, images and metaphors with executives and encourage rigour in the way leaders organise their thinking, visioning, planning and expectations. Furthermore, coaches challenge executives to their own competence or learning edge, and build leaders' capacity to manage their own anxiety in tough situations (O'Neill, 2000; Stern, 2007).

Whitherspoon (2000) describes executive coaching as an actionlearning process to enhance effective action and learning agility, a professional relationship and a deliberate, personalised process, to provide an executive with valid information, free and informed choices based on that information, and internal commitment to those choices.

Kampa-Kokesch and White (2002) conceptualise executive coaching as a formal, ongoing relationship between an individual or team with managerial authority and responsibility in an organisation, and a consultant who possesses knowledge of behaviour change and organisational functioning. The goal of this relationship is to create measurable behaviour change in the individual or collection of individuals (the team), which results in increased individual and organisational performance, and where the relationship between individual or team and consultant facilitates this change by or through giving direct behaviourally based feedback, creating opportunities for change and demanding accountability (Kampa-Kokesch \& Anderson, 2007; Killburg, 2007a). The roles, services and profiles of executive coaches will now be analysed and presented before a prominent executive coaching model is provided as background to the competence executive coaching model.

\section{Roles of executive coaches}

The primary reasons for engaging executive coaches, according to Coutu, Kauffman, Charan, Peterson, Maccoby, Scoular and Grant (2009), are as follows: developing high potentials or facilitating transitions (48\%), acting as a sounding board $(26 \%)$ and addressing derailing behaviour (12\%). Executive coaches are no longer most often hired to usher toxic leaders out of the company. A further major role of the executive coach is to provide feedback to the executive about the executive's behaviour and its impact on others, both those within and outside the organisation (O'Neill, 2000; Witherspoon \& White, 1996, 2007). Through this type of feedback, executives can gain increased self-awareness and self-esteem and improve their communication with peers and subordinates (Killburg, 1996, 2006), which in turn can lead to increased morale, productivity and profits for the organisation (Lowman, 2002; Smith, 1993). Executive coaches can also fulfil the roles of image consultant, role model, management consultant, mentor and taskmaster, personal trainer and confidant(e), information source, therapist/ counsellor and behavioural change agent.

\section{Services provided by executive coaches}

The main services offered by executive coaches are, firstly, skills coaching which involves a dynamic interaction between executive and coach. It requires a deliberate process of observation, inquiry, dialogue and discovery. The essence of coaching executives is helping them to learn instead of training or tutoring them (Kampa-Kokesch, 2003). Secondly, coaching for performance involves interventions to remedy problems that interfere with an executive's job performance or risk derailing a career. Thirdly, in coaching for development (including career and transitional coaching), the concept 'development' is used broadly to refer to the executive's competencies and characteristics required for a future job or role and may entail considerable growth. Over time, an executive's personal growth and development process becomes more open (able to entertain alternative perspectives), differentiated (able to draw from distinctions) and integrated (able to weave these differences into an increasingly complex whole) (Witherspoon, 2000).

Fourthly, coaching for an executive's agenda refers to personal, business and/or organisational issues or concerns. Often this coaching covers important issues for executives and their organisations that are otherwise overlooked, particularly during change initiatives, layoffs or company downsizing. Fifthly, sometimes the sessions for coaching for an executive's agenda border on personal/life coaching, as the executive considers his or her life purpose and personal challenges. Further services provided by executive coaches may include business, remedial and team coaching (Witherspoon, 2000).

\section{Profiles of executive coaches}

The profiles of executive coaches are described in terms of knowledge and skills, competencies and other qualities or characteristics.

\section{Skills and knowledge}

According to Filipezak (1998), business experience is regarded as a vital skill for executive coaches. Psychologists and counsellors with little or no business experience may be ill suited to the role of executive coach. Business experience should be a prerequisite for anyone who identifies himself or herself as an executive coach. Executive coaches should have goal-setting tools, be familiar with strategic planning and know how to plan actions and move forward. Many coaches are therapists or former consultants (Morris, 2000). An executive coach who is knowledgeable about the industry can help a new executive who is not. Executive coaches should understand the organisations they are working in (Underhill, 2007).

A coach can aid the executive in adjusting to the organisational culture and the executive team. Executive coaches working with managers from different countries need to be aware of the influence of local culture on the managers' behaviour. A manager's organisational culture will often be totally different from that of the executive coach, and understanding these differences can help executive coaches to work more effectively (Donnison, 2008). Knowledge of new management techniques and skills is necessary to understand the developmental history and operation of different psychological tests and instruments. According to Morris (2000), the greatest need for coaching at senior level is in new management techniques and skills. Executive coaches should also understand the developmental history of and be knowledgeable about different psychological tests, instruments (intelligence, personality, motivation, cognitive style, managerial style, aptitude) and $360^{\circ}$ methodology (Brotman et al., 1998).

\section{Competencies}

According to Brotman et al. (1998), executive coaches are characterised by the competency to facilitate sustained behaviour change in the work context. The executive is coached to display change in the targeted behaviour(s). This change is consistent, even under pressure or stress (Rothwell \& Sullivan, 2005). The new behaviour is sustained by the internalisation of deeper psychological insights about undesirable behaviour(s) and targeted coaching that converts the insights into pragmatic action steps. This includes, (1) identifying habitual self-defeating scripts and learning how the adverse elements of the scripts erode leadership effectiveness, (2) revealing the truth and fresh insights into what drives the executive, (3) converting insights into observable behaviour change, (4) distinguishing between healthy and more primitive defences and (5) operationalising the self-actualisation pattern congruent with business objectives and the executive's aspirations. Tricky situations involving criticism and blame can be used to facilitate interactional change. The role of the executive coach entails inviting personal and focused criticism and utilising a meta-perspective, as well as anchoring the conversation in the present situational interaction (Brotman, Liberi \& Wasylyshyn, 2007; Kykyri, Puutio \& Wahlstrom, 2007). These competences and competencies provide some of the important outcomes to be achieved in an executive coaching intervention but do not describe the process in an integrated model. 


\section{Qualities/characteristics}

According to Hall, Otazo and Hollenbeck (1999), some of the advantages of external coaches are anonymity, confidentiality, experience in many businesses, expertise in political nuances, being less likely to evaluate and judge, expertise based on extensive experience and being more objective (Sperry, 2007). Gender does not matter in a coaching relationship communication is the main consideration (Quick \& Macik-Frey, 2007). Research has shown that gender, combined with age and position, is sometimes a factor. There is the potential for unethical behaviour. Each organisation should develop its own coaching code of ethics to govern decisions about how coaches are assigned to executives and managers. Further qualities identified by Brotman et al. (1998) are being a trusting and approachable person, being comfortable with different types of people (including top management), having compassion and creativity, being intelligent and having interpersonal and political savvy and sound self-knowledge.

\section{EXECUTIVE COACHING MODELS}

Many executive coaching models exist in the literature, describing the tasks in different phases of the model. In order to address the outcomes-based and competency development models adopted in South Africa, there is a need for a unique competence executive coaching model. In order to develop such as model, various models were consulted and the tasks in each analysed. The following two models are discussed in this article, namely the Strategic Executive Coaching Model (Freas, 2000) and the GROW Model (Alexander, 2006; O'Conner, 2007). These two specific models were chosen because they are well known in industry. The first represents an overview of the whole coaching process, while the second describes the procedure in a single coaching session.

\section{The Strategic Executive Coaching Model}

This model is described as consisting of a number of steps. A short summary is provided on each of these steps.

\section{Step 1: Careful contracting}

It takes skill to create a trusting environment in which open dialogue can occur and underlying issues can be brought to light. A great deal of honest communication and feedback will set the parameters of the executive coaching process. The objectives of the 'contracting dialogue' should include the following, (1) identified success factors for a specific executive's (or team's) current and potential role, (2) agreement on confidentiality boundaries, (3) identification of specific expected business results and (4) confirmation that the 'chemistry' is right to build trust and rapport (Freas, 2000).

Addressing these and other questions will help to define the organisational and individual expectations and support the business objectives. It is imperative that a contracting meeting for the purpose of defining expectations take place before the individual coaching begins. Those attending should typically include a senior-level human resources representative, the executive coach and the executive receiving coaching (Laske, 2007).

\section{Step 2: Comprehensive assessment}

The second step in the executive coaching process is an assessment of each individual executive. Through interviews and formal assessment tools, gaps between the current and expected performance of each executive are identified to measure how the coaching client stacks up against the business context, expected leadership attributes and expected business results (Laske, 2007). The preferred assessment is done through face-to-face interviews with key stakeholders, such as direct reports, peers, bosses and customers, and by shadowing the executive during his or her daily life. The main advantage of the face-to-face approach is that it enables the coach to probe the client and thus provide both quantitative and qualitative feedback (Freas, 2000).

The ultimate value of the assessment process is that the results clearly illustrate areas of strength as well as those requiring attention. This paints a clear picture for the executive in terms of strengths and development opportunities and thus focuses and informs the process. Several executives have described the face-to-face interview method as a $360^{\circ}$ survey that comes to life - a much deeper and more meaningful picture then a written $360^{\circ}$ report (Freas, 2000).

\section{Step 3: Feedback dialogue and action planning}

Feedback dialogue: The first order of business in an effective feedback session is to revisit the agreed-upon objectives and review the ground rules. Properly preparing executives for feedback is crucial to ensuring their willingness to listen, accept, open up and move into action planning. Sessions should occur outside the normal office environment to ensure a more relaxed experience, free of interruptions or ready escape routes (Kilburg, 2007b). A neutral site helps the executive manager provide feedback that may contradict his or her current selfperceptions. The coach must facilitate the feedback flow process, help the executive understand the data and moderate any negative reactions. During the feedback dialogue session, the coach will continue to refer to the business requirements, leader attributes and expected business results, and compare them with current performance. The aim is to work within a framework that directs feedback towards the key objectives of the business (Freas, 2000).

Action planning: The action plan must focus on behaviours that contribute to specific business outcomes. A typical action plan includes the following, (1) strengths and why they are important in the executive's current role, (2) developmental areas, (3) action steps required or interventions needed in areas requiring improvement, as well as leveraging strengths, (4) the type of coaching style that will best suit the development process, (5) active learning or experiential learning suggestions: (6) ways in which direct reports, bosses, peers and others can help, (7) a process for following up with key stakeholders and (8) key milestones (Freas, 2000).

Once the action plan is complete, key stakeholders are invited to validate it. These stakeholders typically comprise the same group involved in the initial assessment interviews. By sharing the action plan with those who were initially interviewed, the executive can be assured that the planned improvements are consistent with expectations. The other advantage of closedloop validation is that it involves those most likely to benefit from a positive change in the executive's behaviour. This process thus fosters their commitment to help the executive develop (Kilburg, 2007b).

\section{Step 4: Active learning}

Once the key stakeholders agree with the plan, a variety of development strategies are implemented. The executive coach guides and reinforces the development strategies, which may include techniques such as action learning, role playing, case study, simulation, video feedback, shadowing and journaling (Laske, 2007). Special developmental courses and team activities are often recommended to support the executive coaching process. The coaching process is usually supported by a series of monthly meetings between the coach, executive and key stakeholders. These dialogues help to ensure that the milestones are being met, the ground rules are being followed and the coaching process continues to be focused on the organisation's business needs (Freas, 2000).

\section{Step 5: Reviewing and sustaining success}

Approximately six months after the feedback session, an abridged version of the initial assessment is conducted to 
determine the impact of the process on the individual and the organisation. The results of the assessment give credit for progress and address areas in which changes are still required or bring attention to necessary mid-course corrections (Kilburg, 2007b). The results of the abridged assessment are shared with key stakeholders to further the development of the executive and ensure alignment to organisational goals. Follow-up is a critical success indicator of the entire executive coaching process. In addition, to ensure overall quality, assessment of the coach is essential (Freas, 2000).

The Strategic Executive Coaching Model is a typical example of a process model, which describes the coaching process by means of a number of steps. The GROW Model, on the other hand, describes the process of a single coaching session.

\section{The GROW Model}

One key role of any leader is to coach team members to achieve their best. A coach will typically help team members to solve problems, make better decisions, learn new skills or otherwise progress in their role or career. One proven approach that helps with this is the GROW Model. This model, devised by Sir John Whitmore, provides a framework both for individual coaching sessions and the whole process. The GROW (Goal, Reality, Options, Wrap-up) Model is one of the most common coaching tools (Graham, 2005).

It enables the coach to structure a coaching conversation and deliver a meaningful result. The discussion should start with a definition of the topic in order to understand what specifically the player wishes to talk about, what territory he or she is in, the scale of the problem, the importance and emotional significance of the topic to the player and his or her long-term vision of goal for the topic. The framework provides a simple four-step structure for a coaching session (Graham, 2005).

\section{Step 1: Goal}

Coach and player identify and agree on a number of clear and achievable goals (outcomes) for the discussion. This goal is not the longer-term objective of the player. The desired outcome is to be achieved within the limits of the discussion (Passmore, 2007). In so doing, it is useful to ask questions such as the following: 'How will you know that you have achieved that goal?' and 'How will you know the problem has been solved?'

This stage thus gives coaching its distinct forward-moving characteristic. It enables the client (and coach) to do the following, (1) be clear about what they are working to achieve, (2) subdivide the goals into smaller, achievable goals, (3) ensure that all actions are geared towards achieving the goals ('begin with the end in mind') (Covey, 1989), (4) ensure that the goals are not in conflict with other goals and (5) develop a compelling future and thus the incentive to take action (Passmore, 2007).

\section{Step 2: Reality}

Both coach and player invite self-assessment and offer specific examples to illustrate their points and achieve the most accurate picture of the topic possible. Useful coaching questions include the following: 'What is happening now?' 'What, who, when and how often?' 'What is the effect or result of this?' This stage thus provides the client with a starting point for moving towards the goals. It enables the client (and coach) to realise achievements, capabilities, behaviour, available resources and empowering beliefs and feelings, whilst challenging limiting beliefs and feelings (Gallwey, 2001).

This assists the client to see the situation from an'outside-in' perspective; the client then often takes action without thinking about it ('awareness is curative') (Gallwey, 2001). The stage also provides the opportunity to review progress during future sessions, creating accountability and identifying new learning and actions.

\section{Step 3: Options}

In the options stage, the coach's intention is to draw out a list of all the possible things the player can do without judgement and evaluation. The coach elicits suggestions from the player by asking effective questions and guides him or her towards making the right choices (Evers, Brouwers \& Tomic, 2006). Typical questions used to establish the options are: 'What else could you do?'; 'What if this or that constraint were removed?'; 'What are the benefits and downsides of each option?'; and 'What factors would you use to weigh up the options?'

This stage thus gives the client support and time to think creatively and differently about how he or she can achieve the goal. This is crucial if the client is going to change behaviour and beliefs. It also provides a powerful and lasting experience of creative thinking (Evers, Brouwers \& Tomic, 2006).

\section{Step 4: Wrap-up}

In this stage, the coach's intention is to gain commitment to action. The coach and player select the most appropriate options, commit to action, define the action plan, the next steps and a timeframe for their objectives and identify how to overcome any obstacles. Useful questions are: 'So what will you do now and when?'; 'What could stop you moving forward?'; 'And how will you overcome it?'; 'Will this address your goal?'; 'How likely is this option to succeed?'; and 'What else will you do?' To achieve goals, greater fulfilment and pleasure, people have to translate dreams into reality. This stage thus completes this, by supporting, encouraging and focusing the client on planning and taking action within useful time scales (Evers, Brouwers \& Tomic, 2006).

The GROW Model works because it ensures that there is nothing at the unconscious level which might prevent the client from going for the goal. It checks whether the goal fits in with the client's capabilities and purpose in life, and establishes whether he or she needs to change any current behaviours or acquire new skills in order to be successful (Passmore, 2007).

From the above discussion on the differences in coaching with other interventions, the description of executive coaching, the roles, services and profiles of coaches and the executive coaching models it is clear that the boundaries of the profession and role are becoming increasingly clear. This growing body of knowledge and the available model in particular help to clarify the crucial competences in executive coaching interventions. As explained before, the authors, however, are of the opinion that few models present a comprehensive description of the competences in executive coaching and the following research process was therefore designed in an attempt to design a competence executive coaching model that will assist in the training of potential coaches.

\section{RESEARCH DESIGN}

The research design is discussed with reference to the research approach, the informants, the procedure and the data analysis.

\section{Research approach}

The study was conducted while one of the authors was involved in teaching doctoral students in consulting psychology and executive coaching, specifically in the USA. The approach involved a literature review of two executive coaching models and a qualitative study using focus groups and content analysis to develop and evaluate the competence executive coaching model (Bryman, 2007).

Although only two models are described in this article, the first group of participants studied the theory of coaching over a sixmonth period while being enrolled in a coaching programme 
as part of their doctoral studies in consulting psychology. The author and the participants studied and analysed a prescribed text and 46 relevant journal articles during the programme. Apart from the prescribed material the participants made 22 two-hour presentations on different aspects of coaching and were requested to supply additional books and journal articles during their presentations, which would explore the theory of coaching beyond the prescribed material. This resulted in the participants being exposed to a representative sample of material in the coaching field. They were also exposed to competency models which are not as commonly used in the USA as in South Africa. This allowed them to evaluate different coaching models from a competence (outcomes-based) approach

When conducting the first focus group, the participants had already completed the programme in coaching and were familiar with the competence models and methodology. The second group of participants comprised practising coaches who were chosen on the basis of their knowledge in both coaching and competence models.

\section{Participants}

Two groups of participants took part in this study. The first group consisted of 25 doctoral students in consulting psychology enrolled in a six-month programme in executive coaching in the USA. The focus group with these students was conducted at the end of the six months after completing the programme. The students included in this sample were between the ages of 25 and 45 , and 63 per cent of them were females. They were respectively in the second, third and fourth years of their doctoral training and had chosen a course in coaching on the strength of their keen interest in the field. Some of the students were already providing coaching services as part of their practices. At the time the focus group was conducted they had already completed the sixmonth programme in coaching and had been exposed to intense theoretical and practical training in the field. The information gathered from this group was used to design the competence executive coaching model.

The second group of participants consisted of eight South African executive coaches working in industry. This group of participants consisted of six males and two females and were chosen on the basis of their knowledge and experience in the field of executive coaching. The candidates had a minimum of five years' coaching experience and a formal qualification in the field. These individuals were involved in a focus group that evaluated the competence executive coaching model.

\section{Procedure}

The procedure in this study first involved a literature study of available coaching and executive coaching models in an attempt to determine whether any competence models exist in the literature. The models were evaluated in terms of how clearly the competences, competencies and coaching process were described in each of the models. The models were also evaluated on the basis of the way in which the assessment criteria were described. This resulted in a better understanding of the most common, prominent and important competences and competencies in executive coaching models. It also involved identifying some of the shortcomings in the competence approach. With this theoretical knowledge as background, the first focus group was conducted.

Participants in the first focus group were asked the following question during a two-and-a-half-hour session: 'What are the most important competences in an executive coaching model?' While the participants generated ideas on the most important tasks involved in executive coaching interventions, the researcher categorised the tasks in clusters for subsequent review and analysis. The participants were also asked to provide an indication of the assessment criteria. The following question was posed: 'When would you know that these competences or outcomes have been successfully met?' The researcher adopted an active facilitation role during the discussion to ensure that all participants participated actively and that all the inputs were clarified and captured. The participants' contributions were captured on flip chart paper for all of them to see and review at the end of the focus group.

The second focus group was conducted after the competence executive coaching model had been conceptualised and designed. The participants were asked to evaluate the functionality and uniqueness of the model. The model was sent to the participants beforehand and they were afforded the opportunity to review it before the focus group. The following question was posed during the focus group: 'How can this competence model assist coaches and students in coaching and how is it different from other coaching models?' The initial reactions were probed and further explored and the researcher made notes on all the feedback comments, which were subsequently analysed.

\section{Data analysis}

The data of the first focus group were analysed using competence or outcomes-based and content analysis methodology. The different tasks generated by the focus group participants were thematically grouped and analysed, and the central competence or outcome in each category identified. These broad categories or competences were integrated into a process model, which represents a logical and workable model for the training of executive coaches. Each of the competences in the model was rewritten in outcomes-based or competence format and the appropriate assessment criteria were identified from the data provided by the first focus group. This allowed the authors to construct a coaching model, which described the coaching process, the different competences and the assessment criteria with which trainers can determine the effectiveness of an executive coaching training programme and coaches can evaluate their own performance.

The data from the second focus group were thematically analysed. The comments of the participants were analysed in two parts. The comments on the functionality of the designed model were first analysed, and this was followed by an analysis of the comments on the uniqueness of the model. The findings of this study are discussed in the next section.

\section{FINDINGS AND DISCUSSION}

The findings are presented on the basis of competence executive coaching model that was developed and the findings of the focus group, which evaluated the model. The literature review revealed that coaching can be distinguished from other interventions such as mentoring, facilitation, consulting and counselling. The main difference in mentoring seems to relate to its technical nature which requires the mentor to have the technical skills and knowledge (including technical subject matter) to successfully assume the role of mentor. In comparison, coaching focuses more on affording coachees or executives opportunities to develop their learning agility through specific action learning strategies in order to enhance their performance instead of only their skills at work.

The differences in respect of facilitation were also clear. Facilitation, which focuses on providing opportunities to clients to learn about the self, focuses more on self-actualisation processes and not as much on the performance of the coachees in their work role. The process is also less directive, given the humanistic nature of the intervention, and it may address personal development needs beyond the boundaries of the work role.

The difference between consulting and coaching can be described in terms of the roles that consultants and coaches 
assume during the intervention. While consultants offer solutions and advice, coaches seldom provide solutions and direct answers, but instead, afford coachees opportunities to explore the effectiveness with which they assume their roles in the organisation. Coaches furthermore provide learning opportunities through a range of techniques, which allows the coachees to explore and learn independently.

It is essential to understand these differences before any attempt can be made to develop a coaching model. This formed the basic boundaries of the model. Equally important was an analysis of the roles, services and profiles of coaches which enabled the researchers to design a model that would address the uniqueness of these roles, services and profiles. The analysis of the different roles of coaches allowed the researchers to gain a better understanding of the importance of an effective contracting phase in the model. During the contracting phase, coaches should be clear about the type of intervention that will be provided. Although some techniques of facilitation, consultation and counselling will be used during the intervention, the coaching intervention should still focus on the coachees' performance within the boundaries of role and organisation. Similarly, the analysis of the services provided valuable information on the different types of coaching services available. Both coach and coachee should also agree on the type of coaching that will be provided and this should be included in the formal contract.

The theoretical analysis of the profiles of coaches, which included their skills, competencies and qualities, revealed a number of significant factors to be considered in designing a coaching model. Regarding the knowledge and skills of coaches, the importance of assessment knowledge and skills was described in a number of resources. This suggested the importance of an assessment phase in the coaching model, which allows both the coach and coachee to gain a detailed understanding of the coachee's levels of performance before and after the intervention.

The findings of the theoretical analysis of the competencies of coaches revealed the need for a thorough understanding of psychological processes and dynamics during coaching sessions. Not only will the coach have to explore underlying psychological processes and dynamics during the coaching sessions, but he or she will also have to address these whenever the coachee receives direct feedback on his or her performance from others. This is especially important during the public dialogue interventions in coaching.

An analysis of the different coaching models suggested that some models aim at describing the process of coaching while others describe the procedures in a specific coaching session. This focused the research even further and suggested that the authors needed to concentrate on an intervention model, a coaching session model or both. In the end, the authors decided to design an intervention model which describes the phases of a complete coaching intervention. None of the models which were reviewed was presented in a competence format and although most models present the tasks in one form or another, none could be found that provided the assessment criteria relating to each competence or outcome.

The findings of the first focus group can be summarised as follows: The group as a whole agreed on the fact that contracting was a key outcome in the intervention, but disagreed on whether this is a process or only a written document. While some participants described the content of what should be included in a written coaching contract, others were more focused on the psychological contracting process between the coach and coachee. Determining an effective working relationship between the coach and coachee was of paramount importance to some of the participants. These participants therefore focused more on the competence which is commonly referred to as chemistry meetings between the coach and coachee to determine the possibility of an effective coaching relationship. Ultimately, a combination of the mechanics and dynamics of this process was included in the model.

The participants were also in agreement about some form of assessment being part of the model. While some participants felt that a formal assessment using competency and psychometric assessments was necessary, a small percentage of them felt that a qualitative assessment in the form of, say, a role analysis could be equally valuable in the assessment of coachees. The point was made that not all underperformance stems from a lack of competence, but that system dynamics could play a significant role in underperformance. In order to explore these and the dynamics operating in the team, qualitative assessments should be considered. This led the authors to believe that the context would play a vital role in the selection of assessment tools. The model therefore includes an assessment and reassessment phase, but does not prescribe the nature of assessment tools to be used.

All the participants identified the need to provide feedback to the coachee as an important competence in the coaching process. Not only does this present the first opportunity to provide meaningful insights to the coachee, but it also forms the basis of any development that follows. The participants also identified the design or development of a development plan as a vital part of the process. The participants grouped a number of tasks under this competence and suggested that the assessment criteria should include reaching agreement on the development plan between the coach and coachee. The participants felt strongly about the fact that the coach should not force his or her development agenda on the coachee. This competence is described as compiling an executive coaching development plan in the final model.

While most participants agreed on the importance of others providing feedback to the coachee on his or her performance as part of the coaching intervention, the group was divided on the form in which the feedback should be given. While some participants felt that this feedback could be given anonymously during a $360^{\circ}$ feedback process in the assessment phase, others felt that face-to-face process feedback on the coachee's progress could be equally beneficial. This process is referred to as the public dialogue phase in the model. The participants did agree that if this intervention forms part of the model, the individuals providing the feedback should be properly trained and the feedback should be confined to feedback sessions only.

The participants concurred that the role-out phase does not only involve conducting the individual coaching sessions, but that the action learning interventions and monitoring of progress should also form part of an implementation phase. The assessment criteria in the implementation phase therefore addresses a number of different areas which will indicate competence in this phase.

The lack of evaluation methodology for the evaluation of coaching interventions left the participants with some unanswered questions. Although all of the participants agreed that some form of evaluation was important, the question arose about the appropriate time for this evaluation. The authors addressed this in the model by suggesting monitoring and evaluation during each of the phases in the model and not only at the end of the intervention.

Figure 1 is a graphic representation of the competence executive coaching model. Each competence in this process model is described after the figure.

As indicated in figure 1, this competence executive coaching model consists of five distinguishable phases, starting with a 


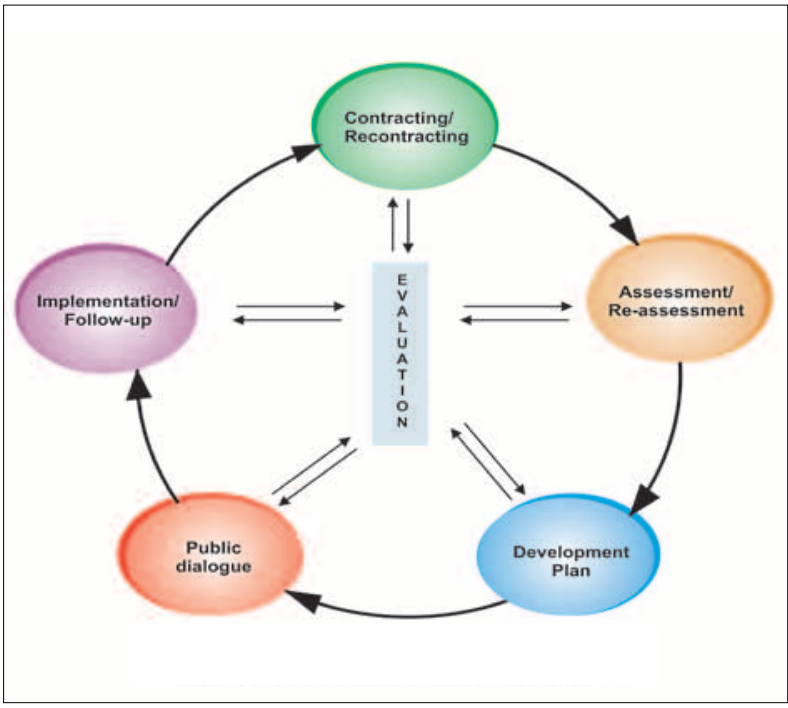

FIGURE 1

Competence Executive Coaching Mode

contracting/recontracting competence. This competence forms the basis of a successful coaching intervention and involves contracting with the business, the relevant parties who will be involved in the intervention and the candidate. Most coaches would agree that it is crucial to understand the context of any business before conducting coaching interventions in it. As part of this analysis, the coach would attempt to understand what the strategy and goals of the organisation are and what type of leadership competencies the business would want to develop in order to achieve these goals more successfully.

In the absence of a leadership profile, the coach can consider developing one for the business. This competence also involves engaging executives and decision makers on the expected outcomes of the intervention. It is advisable to obtain their support and cooperation in the coaching process because this ensures a valuable feedback mechanism for evaluating the success of the intervention. With this as background, the coach can start engaging the coachee and determine the possibility of effective working relationships. The 'chemistry' meetings afford coaches and coachees the opportunity to determine whether they can work together and form a meaningful working relationship. Gender, age, race and experience seem to play a key role in the success of coaching relationships. Initial interactions with the coachee should focus among other things on determining the appropriateness of a coaching intervention.

Coaching is normally used for managers and executives with basic managerial and leadership skills. If it is clear from the first meeting that the coachee does not even have basic leadership competencies, alternative interventions, including formal training, may initially be considered. Similarly, coaches need to determine if the underperformance is the result of a lack of competence or possibly the result of systems dynamics - which in the work context, involves work dysfunctions or even more serious psychopathology. This specific model provides for public dialogue, which involves a structured feedback process during which selected peers provide the executive or leader with feedback on his or her competencies and progress. These parties need to be selected and oriented and their roles and responsibilities in the intervention explained.

Once these basic dimensions of the contract (psychological and physical) have been negotiated, a formal contract is developed. These contracts can run over six or 12 months with monthly coaching sessions of one-and-a-half to three hours. The formal contract normally describes the roles of the coach, coachees and other relevant parties, the expected outcomes, milestones, time boundaries, assessment methodologies to be used and method of payment. Each competence in the model includes an evaluation component at the end. At the end of the first phase the coach takes responsibility for presenting the outcomes of the phase to the relevant parties and obtaining final approval and feedback before starting the next phase. Evaluation questions that need to be asked include the following: Will this intervention and contract reach the expected outcomes? Are the planned intervention and contract in line with the expectations of both the organisation and the coachee? The feedback from relevant parties on the evaluation process is integrated in the contract and final agreement is reached. A second contract can be negotiated at the end of the intervention and a similar process will be involved in recontracting. The assessment criteria in this competence, regarding the contracting and recontracting process, can be summarised as follows:

- Coaches orient themselves to understand the business context.

- Coaches familiarise themselves with the leadership profile in the organisation.

- Consultation takes place with relevant parties on the expected outcomes of the intervention.

- Rapport is established with the coachee (executive) and the expected outcomes are determined.

- The possibility of an effective working relationship is determined.

- The coachee is oriented to the nature of the intervention.

- The appropriateness of a coaching intervention is determined.

- Agreement is reached on the participation of relevant parties.

- An acceptable coaching contract, including cost, is negotiated.

- The contracting process is evaluated in terms of role clarity, expected outcomes, milestones and time boundaries (time, space and task).

- A second contract can be negotiated and developed if required.

The second competence in the model is called assessment/ reassessment and involves a comprehensive assessment of the leadership competencies of the coachee. This is normally based on the leadership/managerial competency framework of the business. In the absence of a competency framework, the coach has to develop an executive competency framework which guides the assessment. Appropriate tools are selected on the basis of the framework and an integrated report generated on the basis of the results. In practice, $360^{\circ}$ evaluations are particularly popular for this purpose in that the results of a self-assessment are compared with the results of an assessment conducted by others. Apart from $360^{\circ}$ evaluations, a number of psychometric assessments can be used for this purpose. A combination of the Hogan Leadership Potential assessment in combination with the Change Style Indicator and the $360^{\circ}$ format of the BarOn Eqi seem to provide meaningful results (Bar-On, 2006; Musselwhite \& Ingram, 1998; Passmore, 2008). These assessments, per se, provide coachees with valuable feedback on their competencies as well as the differences between their self-perceptions and the perceptions of others. An array of other psychometric and leadership assessment tools can be used in order to gain an overall view of the coachees' competencies. Expected levels of performance can be benchmarked against other coachees or employees of the same organisation or organisations in the same industry. Presenting the results and analysing discrepancies between current and expected levels of performance are viewed as an intervention in itself. This is done at the beginning of the next phase. Assessments are also conducted at the end of a coaching cycle to determine the effect of the intervention on the behaviour of the coachee. The coach, however, needs to evaluate the success of this phase before proceeding to the next phase. Evaluation questions that need to be answered include the following: Was this a valid and reliable assessment? What do the relevant parties 
think of the assessment results? Have all the competencies been assessed successfully? If not, what additional assessment may be needed? Did the assessment uncover development needs that were different from those previously expected? In short, the assessment criteria of conducting an executive competency assessment and reassessment phase involve the following:

- An executive leadership competency model is created for the specific organisation.

- Suitable assessment tools for assessing individual development needs, based on the competency model, are identified or developed.

- The coachee's current level of performance is assessed.

- The gaps between current and expected levels of performance are identified.

- The results and assessment process are evaluated in terms of the organisational context, leader profile, expected outcomes (organisation and individual) and contract.

- Corrective steps are taken if necessary.

- A reassessment is conducted after a six-month period.

The development plan competence consists of two components. Firstly, the feedback of the assessment is presented to the coachee and a discovery and internalisation process is facilitated. This is done in a specific structured way in an attempt not to overwhelm the coachee. The second part of this competence consists of constructing a development plan for the coachee. Various actions and learning strategies are used to address the development areas. The development plan can also include shorter formal training or development courses, reading, journaling, presentations and, of course, the formal coaching sessions with the coach. This development plan should be presented to the relevant parties in the organisation in order to evaluate the appropriateness thereof. Evaluation questions that need to be answered include the following: Is this development plan in line with the organisational context, leadership profile of the business and the expected outcomes to be achieved in this coaching intervention? Does this development plan address the important development areas in the coachee's profile? - and if not, it would be necessary to consider additional or alternative development interventions. The competence, regarding the compilation of an executive coaching development plan, has the following assessment criteria:

- Rapport with the executive is re-established and the outcomes to be achieved are reaffirmed.

- An open and honest feedback session on the assessment results is conducted.

- An opportunity to reflect and internalise the assessment results, to ask questions and ventilate feelings is facilitated.

- An integrated summary highlighting strengths and development needs (three each) is presented.

- Agreement is reached on the development areas.

- A structured development plan using appropriate action learning strategies and coaching sessions is developed.

- Agreement on the development plan and process (time, space and task) is reached with the relevant parties.

- The appropriateness of the development plan is evaluated in terms of the organizational context, leader profile, expected outcomes (organisation and individual) and contract.

- Corrective steps are taken if necessary.

The relevant parties involved in the public dialogue competence refer to peers who have been trained in giving feedback on the coachee's progress during structured public dialogue sessions. These parties, who have been trained in the contracting phase of the intervention, provide valuable information on the coachee's behaviour in the work context. Public dialogue sessions are conducted quarterly during one of the coaching sessions and two or three participants give feedback to the coachee on what they have observed in the work context. The coach facilitates this dialogue session and the learning is processed, noted and included in future interventions. Although this may be a somewhat anxiety-provoking experience for a coachee, the coach should contain the situation and ensure that maximum benefit is gained from the interaction. Effective training of the relevant parties in this dialogue is critical. Feedback from these parties may lead to additional development interventions being added or modifications being made to the development plan. This is done after conducting the evaluation process at the end of dialogue session. These competence and assessment criteria, to plan and conduct public dialogue sessions can be summarised as follows:

- The relevant parties are oriented on the nature of executive coaching intervention and the development plan.

- The relevant parties are educated on the importance and value of feedback

- The relevant parties are educated on their roles and responsibilities and appropriate feedback techniques.

- An initial public dialogue session between the executive and the relevant parties is facilitated.

- Agreement is reached between the executive and relevant parties on roles, responsibilities and feedback sessions (time, space and task).

- The feedback from the relevant parties is analysed, noted and incorporated in future interventions.

- Corrective steps are taken if necessary.

Finally, once all these phases have been successfully completed, the intervention can be implemented. This involves exposing the coachee to all the action learning interventions, and conducting the coaching and public dialogue sessions. The progress of the coachee is constantly monitored and corrective actions taken where necessary. A complete assessment will be conducted at the end of the cycle to determine the effectiveness of the intervention. The implementation competence and assessment criteria to implement the executive coaching development plan can be summarised as follows:

- Monthly coaching sessions are conducted with the executive.

- Learning and development processes are facilitated during the coaching sessions.

- It is necessary to facilitate opportunities to reflect on experiences and consider the application of knowledge, skills and competencies in the work context.

- Quarterly public dialogue sessions are facilitated between the executive and relevant parties.

- The action learning activities complementing the coaching sessions are monitored and supervised.

- The effectiveness of the development plan and process is evaluated in terms of the executive's progress, monthly meetings, interactions with relevant parties and feedback received.

- The development plan and process are adapted as necessary.

The findings of the second focus group revealed the following: according to this group, the competence model provides a detailed description of the outcomes to be achieved during a coaching intervention. These competences or outcomes together with the assessment criteria can be used successfully in the training of prospective coaches. The group agreed on the importance of an effective contracting phase. They believe that contracting with the relevant parties is a crucial part of this phase, especially if the coachee was contracted by a contracting organisation. Consulting with the contracting organisation and understanding its needs are equally essential in order to understand the coachee's development needs. Finding a way to include both parties' needs seems to be a real challenge in this process. The group supported the importance of the evaluation process at the end of each phase. They believe that this will improve the effectiveness of the intervention significantly.

The group disagreed about the importance of formal assessment as suggested in the second phase of the model. Not all executive coaches are psychologists and not everyone believes in the importance of formal competency and psychometric assessments. The group had various opinions on this phase. 
While some supported a formal competency and psychometric assessment to determine a baseline, others believed in a less rigorous assessment and proposed using only a $360^{\circ}$ evaluation. At the other end of the continuum, some coaches even believe that assessments are unnecessary and that coach and coachee will determine the development areas together on the basis of the role and needs of the executive without conducting a formal assessment.

Although there was considerable agreement on the importance of a development plan, the group had different views on the public dialogue intervention, which forms part of the model. While some of the group members deemed this to be a valuable tool in the process, others believed it could lead to a breach of confidentiality and expose the executive unnecessarily. Finally, the group mentioned the importance of monitoring throughout the implementation phase. Managing the relationship and keeping the coachee involved and connected between coaching sessions is of paramount importance. Without this, the coachee can easily become disconnected from the coach and the process.

\section{Conclusion}

The literature review provided scant evidence of competence executive coaching models and there seems to be a specific need for this in the training of coaches in South Africa. Hence, the model that was developed is an attempt to provide trainers with a structured model for the training of coaches. The model is presented in competence or outcome format and consists of five unique competences or phases - namely. contracting/ recontracting, assessment/reassessment, a development plan, public dialogue sessions and implementation/follow-up. Each is followed by an evaluation process to determine the effectiveness of the specific phase. The model is regarded as a unique contribution by the research participants in that it describes both the competences and assessment criteria in a coaching process. The findings from the focus group also suggested that the model may help to improve the effectiveness of coaching training programmes. It provides not only a basic model, but also the criteria against which the success of prospective coaches can be measured. The differences relating to the content of the model seem to reflect the individual approaches of different coaches, and although the participants agreed on the usefulness of the model and the competences in general, they believed that the model would be applied somewhat differently by coaches with a psychological background and those from a management or business background. The participants also warned against the perceived risk involved in the use of public dialogue sessions.

\section{REFERENCES}

Alexander, G. (2006). Behavioural coaching - the GROW model. In J Passmore (Ed.), Excellence in coaching: The industry guide. London, Philadelphia: Kogan Page.

Bachkirova, T. (2007). Role of coaching psychology in defining boundaries between counseling and coaching. In S. Palmer \& A. Whybrow, (Eds.). Handbook of coaching psychology: A guide for practitioners. London, New York: Routledge.

Bar-On, R. (2006). The Bar-On model of emotional-social intelligence (ESI). Psicothema, 18, 13-25.

Brotman, L.E., Liberi, W.P., \& Wasylyshyn, K.M. (1998). Executive coaching: The need for standards of competence. Consulting Psychology Journal: Practice and Research, 50, 40-46.

Brotman, L.E., Liberi, W.P., \& Wasylyshyn, K.M. (2007). Executive coaching: The need for standards of competence. In R.R Kilburg \& R.C. Diedrich (Eds.), The wisdom of coaching: Essential papers in consulting psychology for a world of change. Washington: American Psychological Association.

Bryman, A. (2007). Qualitative research II. Los Angeles, London: SAGE.
Coutu, D., Kauffman, C., Charan, R., Peterson, D.B., Maccoby, M., Scoular, P.A. et al. (2009). What can coaches do for you (executive coaches). Harvard Business Review, 87(1), 91-97.

Covey, S.R. (1989). The seven habits of highly effective people. Washington: Free Press.

Clutterbuck, D. (2008). What's happening in coaching and mentoring? And what is the difference between them? Development and Learning in Organisations, 22(4), 8-10.

Diedrich, R.C. (1996). An iterative approach to executive coaching. Consulting Psychology Journal: Practice and Research, $48,61-66$.

Donnison, P. (2008). Executive coaching across cultural boundaries: An interesting challenge facing coaches today. Development and Learning in Organisations, 22(4), 17-19.

Douglas, C.A., \& McCauley, C.D. (1999). Formal development relationships: A survey of organizational practices. Human Resources Development Quarterly, 10(3), 203-220.

Evers, W.J.G., Brouwers, A., \& Tomic, W. (2006). A quasiexperimental study on management coaching effectiveness. Consulting Psychology Journal: Practice and Research, 58(3), 174-182.

Filipezak, B. (1998). The executive coach: Helper or healer? Training, 35(3), 30-36.

Freas, A.M. (2000). Coaching executives for business results. In M.L. Goldsmith \& A.M. Freas (Eds.), Coaching for leadership. San Francisco: Jossey-Bass.

Gallwey, W.T. (2001). The inner game of work. New York: Random House Trade Paperbacks.

Goldsmith, M., \& Lyons, L.S. (2006). Coaching for leadership: The practice of leadership coaching from the world's greatest coaches. San Francisco: Pfeiffer.

Graham, A. (2005). Supercoaching: The missing ingredient for high performance. London: Random House Business.

Hall, D.T., Otazo, K.L., \& Hollenbeck, G.P. (1999). Behind closed doors: What really happens in executive coaching. Organizational Dynamics, 27(3), 39-53.

Harris, M. (1999). Look, it's an I-O psychologist ... no, it's a trainer ... no, it's an executive coach. TIP, 36 (3), 1-5.

Hart, V., Blattner, J., \& Leipsic, S. (2007). Coaching versus therapy: A perspective. In R.R Kilburg \& R.C. Diedrich (Eds.), The wisdom of coaching: Essential papers in consulting psychology for a world of change. Washington: American Psychological Association.

Kampa-Kokesch, S., \& Anderson, M.Z. (2001). Executive coaching a comprehensive review of the literature. Consulting Psychology Journal: Practice and Research, 53(4), 205-228.

Kampa-Kokesch, S., \& White, R.P. (2002). The effectiveness of executive coaching: What we know and what we still need to know. In R.L. Lowman (Ed.), The handbook of organizational consulting psychology. San Francisco: Jossey-Bass.

Kampa-Kokesch, S. (2003). Executive coaching as an individually tailored consultation intervention: Does it increase leadership? Ann Arbor: UMI

Kampa-Kokesch, S., \& Anderson, M.Z. (2007). Executive coaching: A comprehensive review of the literature. In R.R Kilburg \& R.C. Diedrich (Eds.), The wisdom of coaching: Essential papers in consulting psychology for a world of change. Washington: American Psychological Association.

Kiel, F., Rimmer, E., Williams, K., \& Doyle, M. (1996). Coaching at the top. Consulting Psychology Journal: Practice and Research, 48, 67-77.

Killburg, R.R. (1996). Toward a conceptual understanding and definition of executive coaching. Consulting Psychology Journal: Practice and Research, 48, 134-144.

Killburg, R.R. (2000). Executive coaching: Developing managerial wisdom in a world of chaos. Washington: American Psychological Association.

Killburg, R.R. (2006). Executive wisdom: Coaching and the emergence of virtuous leaders. Washington: American Psychological Association.

Killburg, R.R. (2007a). Toward a conceptual understanding and definition of executive coaching. In R.R Kilburg \& R.C. Diedrich (Eds.), The wisdom of coaching: Essential papers in consulting psychology for a world of change (pp. 21-30). Washington: American Psychological Association. 
Killburg, R.R. (2007b). Facilitating intervention adherence in executive coaching: A model and methods. In R.R Kilburg \& R.C. Diedrich (Eds.), The wisdom of coaching: Essential papers in consulting psychology for a world of change (pp. 241-255). Washington: American Psychological Association.

Killburg, R.R., \& Diedrich, R.C. (2007). The wisdom of coaching: Essential papers in consulting psychology for a world of change. Washington: American Psychological Association.

Koortzen, P., \& Cilliers, F. (2002). The psychoanalytic approach to team building. In R.L. Lowman (Ed.), The handbook of organizational consulting psychology. San Francisco: JosseyBass.

Kykyri, V.L., Puutio, R., \& Wahlstrom, J. (2007). Inviting interactional change through 'tricky situations' in consulting: Handling criticism and blame. Journal of Organizational Change Management, 20(5), 633-651.

Laske, O.E. (2007). Integrated model of developmental coaching. In R.R Kilburg \& R.C. Diedrich (Eds.), The wisdom of coaching: Essential papers in consulting psychology for a world of change. Washington: American Psychological Association.

Levinson, H. (1996). Executive coaching. Consulting Psychology Journal: Practice and Research, 48, 115-123.

Levinson, H. (2002). Organizational assessment: A step-bystep guide to effective consulting. Washington: American Psychological Association.

Levinson, H. (2009). Consulting psychology: Selected articles. Washington: American Psychological Association.

Lowman, R.L. (2002). The California School of Organizational Studies handbook of organizational consulting psychology: A comprehensive guide to theory, skills, and techniques. San Francisco: Jossey-Bass.

Neuman, W.L. (2007). Basics of social research: Qualitative and quantitative approaches. Boston: Pearson/Allyn \& Bacon.

Morris, T.W. (2000). Coaching: Rebirth of an age-old remedy. Afp Exchange, 20(3), 34-36.

Musselwhite, W.C., \& Ingram, R.D. (1998). Change style indicator facilitator's guide. San Francisco: Jossey-Bass.

O'Conner, J. (2007). How coaching works: The essential guide to the history and practice of effective coaching. London: A. \& C. Black.

O'Neill, M.B. (2000). Executive coaching with backbone and heart: A systems approach to engaging leaders with their challenges. San Francisco: Jossey-Bass.

Palmer, S., \& Whybrow, A. (2007). Handbook of coaching psychology: A guide for practitioners. London; New York: Routledge.

Passmore, J. (2007). Coaching and mentoring: The role of experience and sector knowledge. International Journal of Evidence Based Coaching and Mentoring (special issue), 10-16.

Passmore, J. (2008). Psychometrics in coaching: Using psychological and psychometric tools for development. London: Philadelphia.

Peterson, D.B. (1996). Executive coaching at work: The art of one-on-one change. Consulting Psychology Journal: Practice and Research, 48, 78-86.

Quick, J.C., \& Macik-Frey, M. (2007). Behind the mask: Coaching through deep interpersonal communication. In R.R Kilburg \& R.C. Diedrich (Eds.), The wisdom of coaching: Essential papers in consulting psychology for a world of change (pp. 311317). Washington: American Psychological Association.

Richard, T.R. (1999). Multimodal therapy: A useful model for the executive coach. Consulting Psychology Journal: Practice and Research, 51(1), 24-30.
Rothwell, W.J., \& Sullivan, R. (2005). Practicing organization development: A guide for consultants. San Francisco: Pfeiffer.

Salters, L. (1997). Coaching and counselling for peak performance. Business and Economic Review, 44(1), 26-28.

Saporito, T.J. (1996). Business-linked executive development: Coaching senior executives. Consulting Psychology Journal: Practice and Research, 48, 96-103.

Schein, E.H. (1969). Process consultation. Reading: AddisonWesley.

Schein, E.H. (1987). The clinical perspective in fieldwork. Newbury Park: Sage.

Schein, E.H. (1988). Process consultation. Reading: AddisonWesley.

Schein, E.H. (1999). The corporate culture survival guide: Sense and nonsense about culture change. San Francisco: Jossey-Bass.

Schein, E.H. (2005). Practicing organisation development: A guide for consultants. San Francisco: Pfeiffer.

Schein, E.H. (2006). Coaching for leadership: The practice of leadership coaching from the world's greatest coaches. San Francisco: Pfeiffer.

Smith, L. (1993). The executive's new coach. Fortune, 128(16), $126-128$.

Sperry, L. (1993). Working with executives: Consulting, counselling and coaching. Individual Psychology, 49(2), 257-266.

Sperry, L. (1996). Corporate therapy and consultation. New York: Brunner/Mazel.

Sperry, L. (2007). Leadership dynamics: Character and character structure in executives. In R.R Kilburg \& R.C. Diedrich (Eds.). The wisdom of coaching: Essential papers in consulting psychology for a world of change (pp. 291-302). Washington: American Psychological Association.

Stern, L.R. (2007). Executive coaching: A working definition. In R.R Kilburg \& R.C. Diedrich (Eds.). The wisdom of coaching: Essential papers in consulting psychology for a world of change (pp. 31-38) Washington: American Psychological Association.

Tobias, L.L. (1996). Coaching executives. Consulting Psychology Journal: Practice and Research, 48, 87-95.

Torrance, E.P. (1984). Mentor relationships: How they aid creative achievement, endure, change, and die. New York: Bearly.

Underhill, B.O. (2007). Executive coaching for results: The definite guide to developing organizational leaders. San Francisco: Berrett-Koehler.

Witherspoon, R. (2000). Starting smart: Clarifying coaching goals and roles. Coaching executives for business results. In M.L. Goldsmith \& A.M. Freas (Eds.), Coaching for leadership (pp. 165-185). San Francisco: Jossey-Bass.

Witherspoon, R., \& White, R.P. (1996). Executive coaching: A continuum of roles. Consulting Psychology Journal: Practice and Research, 48, 124-133.

Witherspoon, R., \& White, R.P. (2007). Executive coaching: A continuum of roles. In R.R Kilburg \& R.C. Diedrich (Eds.), The wisdom of coaching: Essential papers in consulting psychology for a world of change (pp. 103-111). Washington: American Psychological Association. 